DOI: $10.14451 / 1.201 .169$

\title{
СИСТЕМА ПОКАЗАТЕЛЕЙ ДЛЯ ОЦЕНКИ ТУРИСТИЧЕСКОЙ ДЕЯТЕЛЬНОСТИ В РФ *
}

\author{
(C) 2021 Гизатуллина О.М. \\ кандидат экономических наук, доцент Департамента бизнес- аналитики \\ Финансовый университет при Правительстве Российской Федерации, Россия, Москва \\ E-mail: OMGizatullina@fa.ru
}

Туристический сектор переживает масштабную трансформацию. На сегодняшний день развитие внутреннего туризма стало одним из приоритетов экономической политики России. В ближайшее время будет полностью обновлен закон о туризме, который будет полностью отвечать реалиям современности, так же планируется увеличение в два-три раза основных показателей туристической отрасли. Статистическая информация в туризме имеет особый межотраслевой и социальноэкономический характер.

Ключевые слова: туризм, статистическая отчетность, показатели оценки туристической деятельности, экономическая эффективность развития туризма.

Важным приоритетом экономической политики РФ является развитие туризма. Основные направления по совершенствованию данной сферы закреплены в Стратегии развития туризма до 2035 года. В результате от реализации стратегии ожидается увеличение количества внутренних туристических поездок примерно в два раза, трехкратное увеличение инвестиций с туристическую сферу и в целом существенный рост индустрии, включая экспорт туристических услуг. Несмотря на то, что туристическая отрасль Российской Федерации одна из первых отраслей экономики, которая попала под удар коронавирусной инфекции, в долгосрочной перспективе приоритеты развития останутся неизмененными. Ростуризм оценивает финансовые потери туристической индустрии РФ за 2020 год в 1,3 трлн. рублей.

Рассмотрим распределение выручки от реализации туристского продукта на основе ОКВЭД 2. Крайне важно иметь представление, каким образом происходит распределение выручки (без налога на добавленную стоимость, акцизов и аналогичных обязательных платежей) по собирательной группировке «Туризм» на основе ОКВЭД 2 в разрезе группировок видов экономической деятельности в нее входящих по состоянию на 2019 год (рисунок 1).

Виды экономической деятельности, входящие в группировку «Туризм»:

1 - Пассажирские перевозки
2 - Деятельность по предоставлению услуг общественного питания

3 - Размещение посетителей

4 - Деятельность туристических фирм и деятельность в сфере предоставления услуг по бронированию

5 - Деятельность в сфере культуры

6 - Розничная торговля туристическими товарами

7 - Прочие

Из данного анализа видно, что наибольшую долю от выручки приносят пассажирские перевозки.

Проведем анализ распределения числа организаций по собирательной группировке «Туризм» в соответствии с ОКВЭД 2 в разрезе группировок видов экономической деятельности, входящих в нее в 2019 г. (рисунок 2). Интересно заметить, что количество организаций, занимающихся пассажирскими перевозками, намного меньше, чем организаций в сфере услуг общественного питания; наибольшую долю занимает общепит и туристские фирмы в сфере бронирования и в сфере размещения посетителей.

Органы государственной статистики получают статистические данные от юридических и физических лиц. Данные сведения содержат информацию о финансово-хозяйственной деятельности организаций туристической отрасли. На основании данной статистической информации строятся динамические ряды в течении

\footnotetext{
* Статья подготовлена по результатам исследований, выполненных за счет бюджетных средств по государственному заданию Финуниверситету
} 
Распределение выручки (без НДС, акцизов и аналогичных обязательных платежей) по собирательной группировке "Туризм" на основе ОКВЭД2 в разрезе группировок видов экономической деятельности в нее входящих в 2019 г., в \%

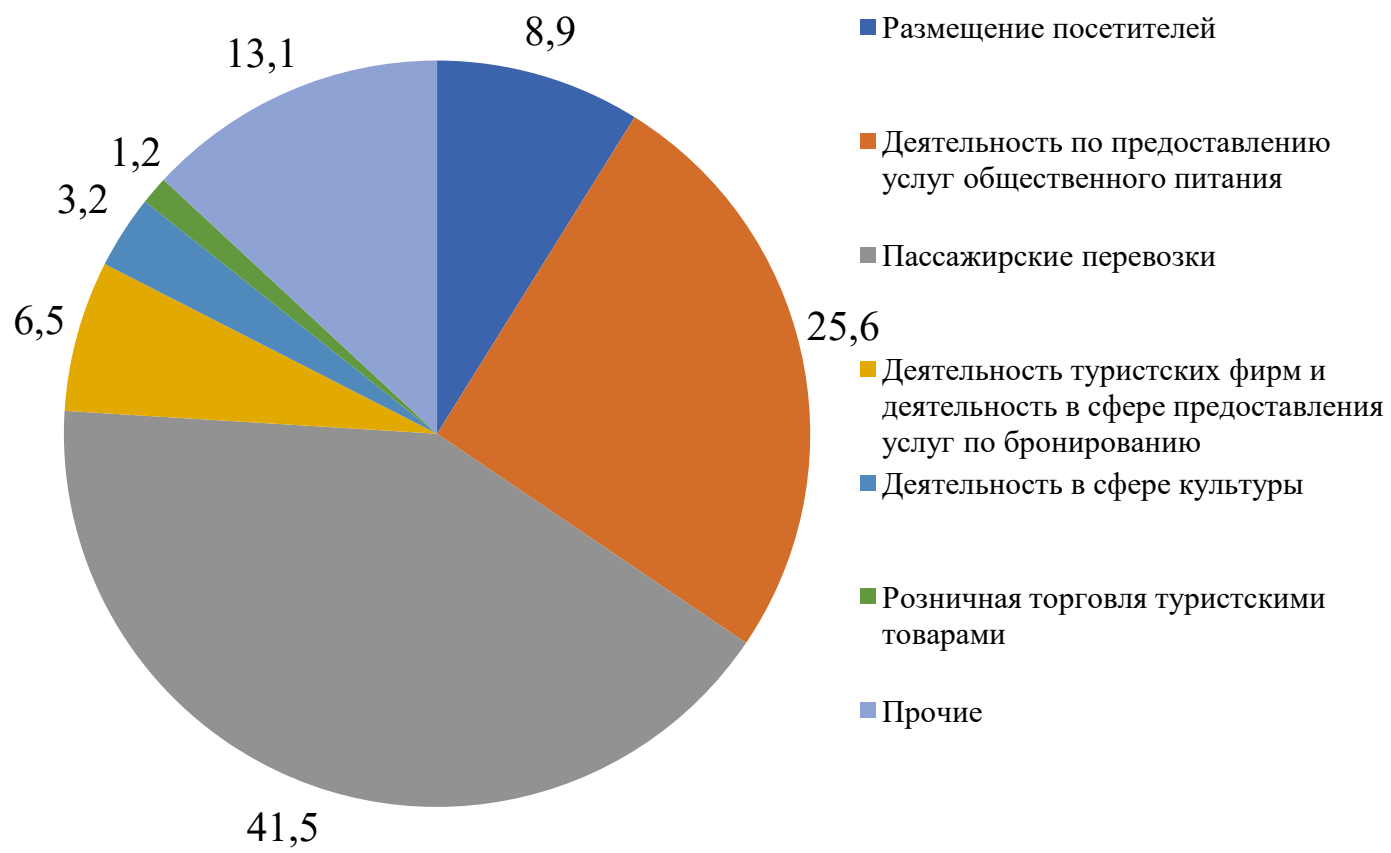

Рисунок 1. Распределение выручки (без налога на добавленную стоимость, акцизов и аналогичных обязательных платежей) по собирательной группировке «Туризм» на основе ОКВЭД 2

\section{Распределение числа организаций по собирательной группировке "Туризм" на основе ОКВЭД 2 в разрезе группировок видов экономической деятельности в нее входящих в 2019 г., в \%}

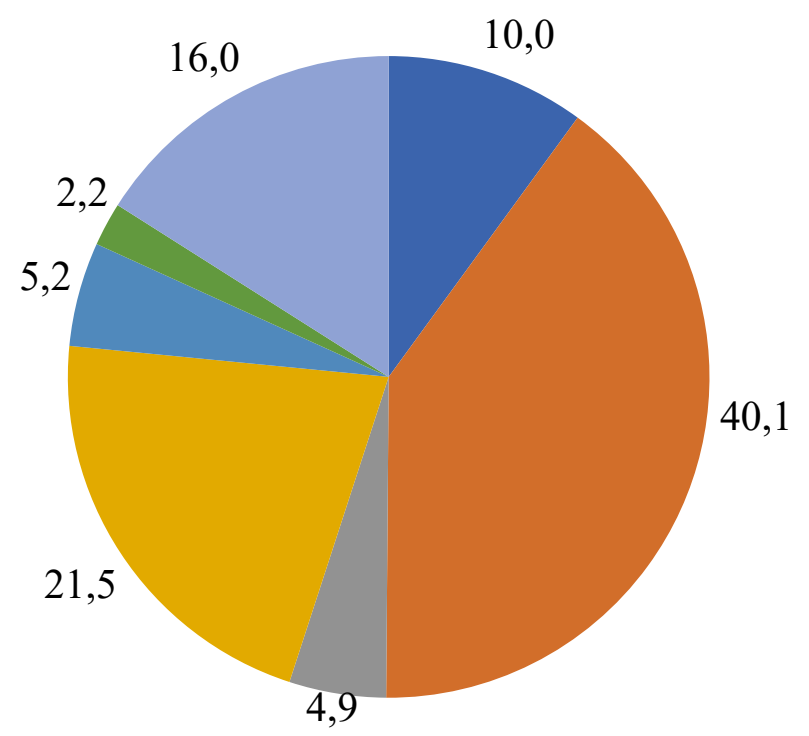

— Размещение посетителей

— Деятельность по предоставлению услуг общественного питания

п Пассажирские перевозки

- Деятельность туристских фирм и деятельность в сфере предоставления

- Делуг по бронированию

- Розничная торговля туристскими товарами

П Прочие

Рисунок 2. Распределение числа организаций по собирательной группировке «Туризм» на основе ОКВЭД 2 в разрезе группировок видов экономической деятельности в нее входящих в 2019 г. 
длительного периода времени.

Для оценки эффективности финансовохозяйственной деятельности туристических организаций используется ряд показателей.

Сводные натуральные показатели содержат качественную оценку туристской деятельности в Российской Федерации или в регионе [1]:

- число занятых в туристских организациях

- численность детских оздоровительных учреждении

- количество обслуженных туристов туроператорскими и турагентскими компаниями

- количество посетителей государственных природных заповедников и национальных парков

На основе индивидуальных показателей, которые содержатся в статистической отчетности, формируется информационная база по следующим направлениям:

- поездки граждан за границу по целям, поездки иностранных граждан в Россию по целям

- деятельность средств размещения

- деятельность туроператорских и турагентских компаний

- деятельность детских оздоровительных учреждении

- туристская деятельность в природных заповедниках и национальных парках

Классификация показателей статистики туризма включает две группы:

1. показатели, туристического спроса и туристического предложения;

2. показатели, характеризующие вклад туризма в национальную экономику.

Показатели туристского спроса включают информацию об объеме, структуре и различных характеристиках туристского потока, которые классифицируются на:

- общие показатели, которые характеризуют число прибытий внутренних и международных посетителей, продолжительность пребывания;

- показатели по сферам.

Для определения объемов международных туристских потоков в Российской Федерации используется форма отчетности «Сведения о количестве иностранных граждан, посетивших Россию, и граждан России, выехавших за границу» (№ 1-ИНТ (спец), приложение 2). Форма отчетности включает шесть разделов:

1) количество граждан России, выехавших за границу, по целям поездки (с выделением цели «Туризм»);

2) количество граждан России, выехавших за границу, по видам транспорта;

3) количество иностранных граждан, посетивших Россию, по целям поездки (с выделением цели «Туризм»);

4) количество иностранных граждан, посетивших Россию, по видам транспорта;

5) количество иностранных граждан, выехавших из России, по целям поездки (с выделением цели «Туризм»);

6) количество иностранных граждан, выехавших из России, по видам транспорта [2].

«Экономические показатели туристского спроса представлены в основном различными видами туристских расходов. При составлении платежного баланса используют общую величину расходов на въездной и выездной туризм. При проведении других экономических расчетов аналитики чаще всего используют средние величины общих или ежедневных расходов посетителя, а также средние расходы одного посетителя на отдельные услуги» [2].

Для оценки экономической эффективности развития туризма на микроуровне используется система показателей, показанная в таблице 1.

Показатели развития туризма применяются для оценки экономической эффективности деятельности туристических фирм, для анализа состояния туристического рынка в целом, а также для выработки управленческих решений на туристическом ранке.

На основе данных статистической отчетности формируется информационная база, характеризующая туристические услуги, социальноэкономические характеристики туристов, цели и сроки поездок.

«В современных условиях возросла потребность в статистической информации в сфере туризма, поэтому Росстат постоянно совершенствует формы статистической отчетности. В настоящее время организации и индивидуальные предприниматели, осуществляющие размещение туристов, отчитываются перед Росстатом по форме № 1-КСР «Сведения о деятельности коллективного средства размещения» (утверждена Росстатом от 27 июля 2012 г. № 422, приложение 3)» [2].

Показатели туристического предложения включают:

- общие сведения, о коллективном средстве размещения 

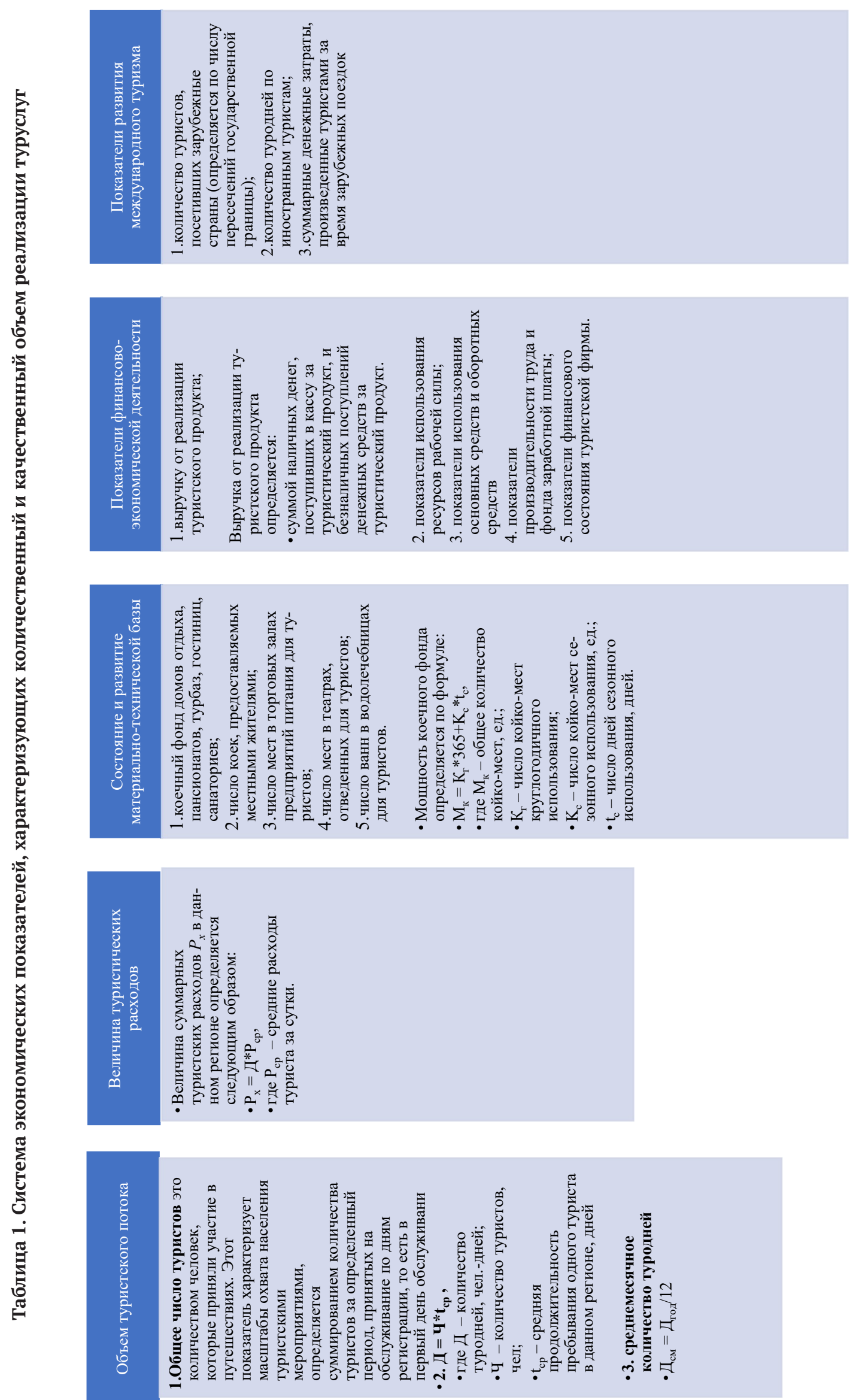
- номерной фонд

- сведения о размещенных лицах

- распределение численности размещенных по целям

- распределение численности размещенных по продолжительности

- сведения о персонале

- основные показатели финансово-хозяйственной деятельности

На официальном сайте Росстат публикует статистические показатели, которые следует учитывать при формулировке стратегии и принятии управленческих решений (таблица 2).

Система показателей в сфере туризма играет важную роль для оценки эффективности функционирования туристических организаций и туристической отрасли в целом, выявления тенденций и изменения состояния отрасли, проведения сравнительного анализа, составления отчетности и принятия грамотных управленческих решений.

\section{Таблица 2. Показателями развития туризма в Российской Федерации}
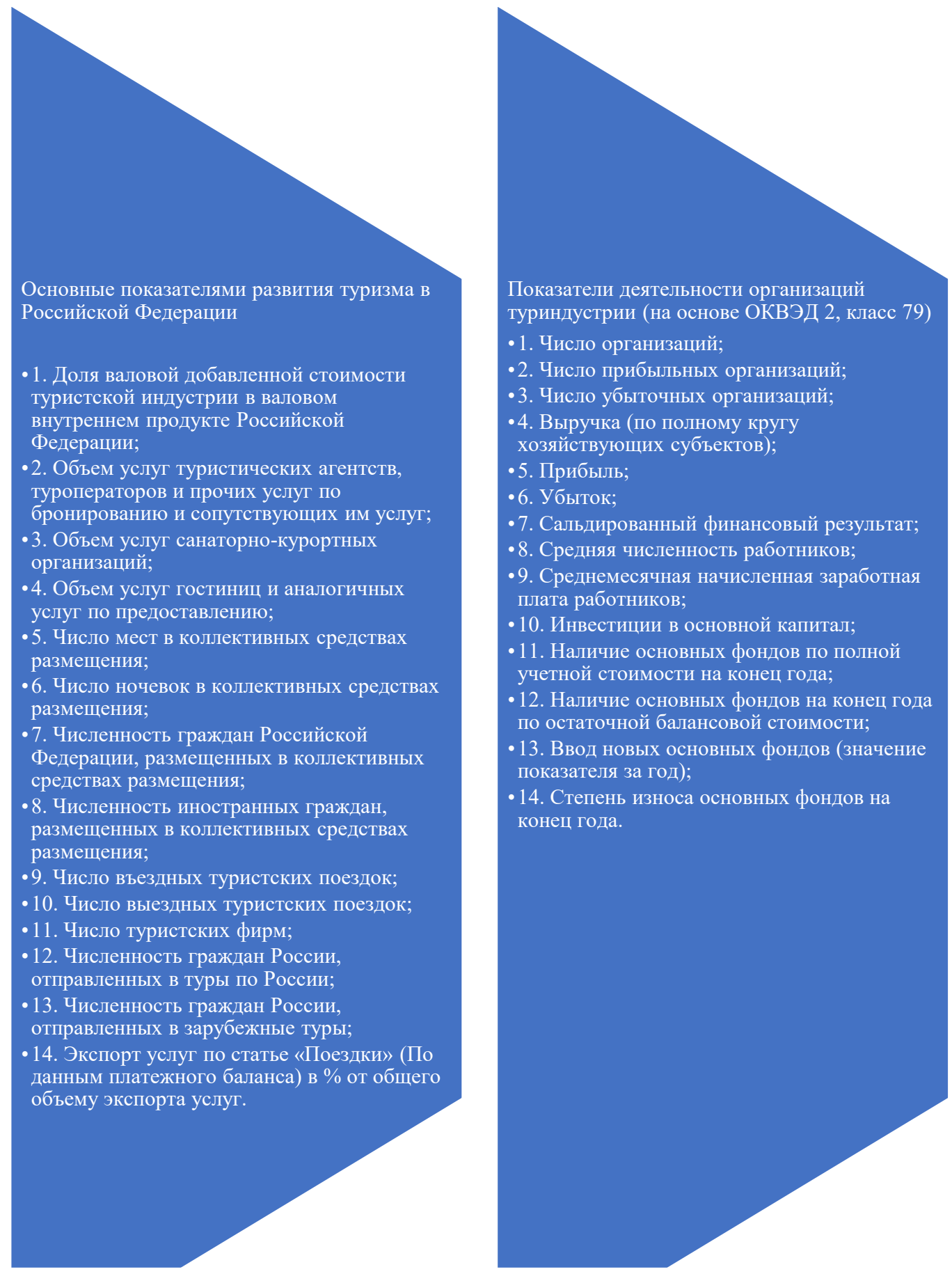


\section{Библиографический список}

1. Статистические показатели. Система показателей статистики туризма. [Электронный pecypc] URL: https:// studref.com/672900/turizm/statisticheskie_pokazateli_sistema_pokazateley_statistiki_turizma

2. Статистика туризма: учебник / коллектив авторов; под ред. А. Ю. Александровой.- М.: Федеральное агентство по туризму, 2014. - 464 с.

3. Федеральная служба государственной статистики (РОССТАТ). Официальная статистическая методология оценки численности въездных и выездных туристических поездок. [Электронный ресурc] URL: https:// rosstat.gov.ru/storage/mediabank/pr640.pdf 